\title{
The Perspective of People Receiving Food Support
}

\author{
Ahuva Even-Zohar \\ Ariel University
}

The research examines the perspective of Israelis assisted by Non-governmental organization (NGOs) to promote their food security. This qualitative study employed the Interpretive Phenomenological Approach. The sample consisted of 16 recipients of food support aged 33-62, and they were interviewed in-depth semistructured protocol.

Five main themes emerged: The background of food insecurity; Forms of food support; The experience of receiving food support; The effect of the assistance on food security; and the responsibility for food security. The participants indicated that the state welfare system should be responsible for food security, and they prefer payment cards that enable them to purchase food suitable to their individual needs while maintaining their dignity. Although the support provided does not entirely extricate families from food insecurity, they gain confidence by being able to receive food in times of hardship. The findings indicate the importance of considering the opinions of those in need when making policy decisions regarding food security.

Keywords: food security, non-governmental organization

\section{INTRODUCTION}

Food security is the ability to access to enough food for an active, healthy life. But some individuals and households experience food insecurity at times during the year. Food insecurity, defined as the limited availability or inability to reliably and regularly procure nutritious food because of a lack of money and other resources, is a serious problem in many industrialized countries (Bickel et al., 2000; Coleman-Jensen, 2019). The underlying causes of the condition lie in economic crisis or recession, the decline of the welfare state, and globalization, any of which can lead to a rise in unemployment, debt, and a reduction in purchasing power. The consequent cuts in the benefits granted to low-income families do not enable them to obtain the food required to meet their needs (Leisinger et al, 2002; Loopstra et al., 2015; Reeves et al., 2017).

Statistics show that in 2018, $11.1 \%$ of the households in the US and $18 \%$ in twenty-eight European countries were food insecure (Coleman-Jensen et al., 2019; Davis \& Geiger; Loopstra et al., 2016). In Israel, a survey from 2016 (Endeweld et al., 2018) found 17.8\% of the households suffering from food insecurity, of which about half were $(8.8 \%)$ severely food insecure. They consisted primarily of families in which the sole source of income was social benefits, the head of the household had only an elementary school education, both parents were unemployed, or there was only one provider. In addition, food insecurity was prominent in large families (four or more children), Arab households, and single-parent families. 


\section{Methods for Dealing With Food Insecurity}

In addition to government benefits, such as the food stamps issued in the US, numerous charitable programs operate in various countries to help promote food security by non-profit organizations, private business (Farhat et al., 2019) For example, in the US, Canada, and Europe, food banks collect donations for those in need, and meal centers or soup kitchens offer hot meals (Owen \& Baumberg, 2017; PettoelloMantovani, et al., 2018; Pruitt et al., 2016). In Israel, assistance is largely provided by NGOs by means of food baskets or hot meals either delivered to the home or distributed at collection points or meal centers. In 2017, the Department of Social Services initiated a national food security program whereby families in need receive a monthly stipend of 146 dollars, half in the form of an electronic payment card for use in supermarkets and the other half in the provision of fruit, vegetables, and dry foods. The program also offers help in applying for the benefits to which families are entitled, as well as workshops on nutrition and money management Endeweld et al., 2018).

\section{The Attitude of Recipients of Food Assistance}

The results of twenty qualitative studies conducted in industrialized countries between 1999 and 2015 (Middleton et al., 2018) reveal that while people using the services of food banks appreciated the assistance, for most the experience was negative. They were grateful to the volunteers, but at the same time reported consistently on the inability to choose the food provided, so that they often received food they were not accustomed to eating, did not know how to prepare, or that was of poor quality. Moreover, for many, the food bank was their last resort, leading to feelings of embarrassment, shame, humiliation, and stigma. Studies conducted in Australia (Booth et al., 2018a; (Booth et al., 2018b) show that although the recipients of food support were thankful for the assistance, they felt they were forced to pay a heavy emotional price because of their situation, and felt invalidated by the way in which the support was provided. They noted their preference for help that gave them power and autonomy, such as supermarket coupons which enabled them to choose food that was healthier, more varied, and more suitable to their needs, and to do so in a socially acceptable manner. Studies from the US (Mousa \& Freeland-Graves, 2019; Parks et al., 2019) indicate that most visitors to meal centers and recipients of food support indeed suffered from food insecurity. The assistance they received not only increased their food security, but also reduced the economic stress they were under and enabled them to use their money for other household needs. Furthermore, a review of thirty-two studies of the experience of food insecurity in the US, Canada, and Australia (Piaskoski et al., 2020) suggests the need for interventions to enhance the coping skills of people receiving food support, as well as to improve the systems providing this support.

A study evaluating the national program for food security in Israel (Endeweld, 2018) similarly found that while it ameliorated the condition of the recipients, given that the starting point for most of the families was extremely low, many of them still remained food insecure. In addition, it was found that the participants were satisfied with the way they were treated and with the amount, quality, and variety of food they received, but preferred assistance in the form of money rather than food products.

Recent years have seen heightened interest in the issue of food insecurity, along with closer examination of the ways in which assistance is provided, particularly in the last year because of the global pandemic (COVID-19). The pandemic has exacerbated economic vulnerabilities, increased unemployment, and caused food insecurity in many countries (e.g. Boyact-Gündüz et al., 2021; Kansiime et al., 2021; Kent et al., 2020; O'Hara et al., 2021; Owens, 2020; Patrice et al., 2020). The current study sought to further this line of inquiry by increasing our understanding of how food insecure individuals in Israel experience the receipt of food support. Although the present study was conducted before the outbreak of the pandemic its findings can help assess the situation of the people who need food support.

\section{METHOD}

\section{Procedure and Participants}

The study adopted a qualitative design based on interpretative-phenomenological approach (Smith \& Osborn, 2003; Smith et al., 2009) in an attempt to understand the meaning of food support from the 
perspective of the recipients themselves. After receiving approval from the university Ethics Committee, participants were recruited through social workers in local welfare departments and the directors of meal centers and food banks. Individuals who agreed to take part in the study were contacted by social work students to arrange a time and place for the interview. Most of the interviews took place in the participant's home. At the start of the meeting, the purpose of the study was explained, and anonymity and confidentiality were ensured: all the names that appear in this paper are fictitious, and no mention is made of the place of residence or the source of the food support. Following this explanation, the interviewees gave their signed informed consent to participate.

The interviews were conducted in 2017-2018 and lasted from forty to ninety minutes. They employed an in-depth semi-structured protocol, and were recorded and transcribed with the consent of the participants. The sample consisted of 16 Jewish Israelis. The sociodemographic characteristics of the interviewees are presented in Table 1.

TABLE 1

SOCIODEMOGRAPHIC CHARACTERISTICS (N=16)

\begin{tabular}{|l|l|c|}
\hline Age (range) & & $33-62$ \\
\hline Gender & Men & 7 \\
\hline & Women & 9 \\
\hline Marital status & Single & 4 \\
\hline & Married & 2 \\
\hline Source of income & Divorced / Separated & 10 \\
\hline & Work & 2 \\
\hline & Work + Welfare benefits & 4 \\
\hline Education & Welfare benefits & 10 \\
\hline & Elementary & 5 \\
\hline Ethnicity & High school & 11 \\
\hline & European & 5 \\
\hline Level of Religiosity & Asian-African & 11 \\
\hline & Religious & 7 \\
\hline & Traditional & 6 \\
\hline & Secular & 3 \\
\hline
\end{tabular}

\section{Data Analysis}

The interviews were subjected to content analysis performed in three stages. First, the transcripts were read and reread a number of times. The texts were then divided into units of meaning. Finally, the units were compared and five main themes were identified.

\section{RESULTS}

\section{Theme 1: Background of Food Insecurity}

Category 1: Reasons for Requesting Food Support

The participants all reported having undergone some sort of crisis, such as economic hardship, a decline in functioning, or loss of family support. Although many were contending with more than one challenge, their main reason for requesting assistance was financial need. Thus, Ronit, a recently separated woman, explained:

I separated [from my husband] a few months ago. Before that, the family income was just fine...I separated and immediately asked [for help]. I'm not getting any alimony yet. 
Similarly, Jacob, a single father raising two daughters, stated:

I got into this situation because at the beginning with the girls I couldn't work. The change [when they came to live with me] was a psychological crisis for them. I didn't work for seven months, and that put me under financial pressure.

Category 2: Previous Ways of Dealing With Food Insecurity

The majority of participants reported that before requesting food support they had been helped by close family, neighbors, and friends. Dorit, for example, described the help she had received from her family.

My sister helped. She lives nearby. And I simply cut back. I got help from the family and good friends, from neighbors.

Several interviewees attempted to deal with the problem on their own, without turning to their family. Jacob explained that there was no one he could ask for help.

I cashed in my pension and savings plans. I didn't get help from anyone. I don't have a family that can help me out.

\section{Theme 2: Forms of Food Support}

Category 1: Food Banks

All the participants received assistance from volunteer organizations running food banks. Shlomit described the difficulties she had encountered in the past and the positive change that had taken place.

The welfare services used to send me to some place...to get food baskets. I had to go there, leave the children at home and go get the baskets...It wasn't accessible, it was inconvenient, hard. I gave up on it...This way, when they bring it to your house, it makes it so much easier and it's very helpful.

Category 2: Meal Centers (Soup Kitchens)

Participants who made use of meal centers attributed this decision to the fact that they lived alone. As David put it:

I'm not married, so I'm the only one who eats. I get here early and wait for them to open. Sometimes I'm even here at seven in the morning.

Sarah reported that she began eating at a meal center after she stopped receiving food baskets.

That's where I eat lunch [the main meal]...I know I'll have one regular meal every day.

Like other participants, she stated that the food was good and the portions generous, but the meal was not nutritious enough.

A little healthiness is missing. More salad and different vegetables.

Category 3: Payment Card Issued by Local Welfare Departments as Part of the National Food Security Program

All the participants receiving this form of support remarked that they preferred it over food baskets. In Dinah's words: 
It used to be baskets... We threw a lot of things out. Then they changed it to a card, and it's better.

Meirav added:

I get a payment card and food baskets...Sometimes they invite me to a workshop on money management.

\section{Theme 3: The Experience of Receiving Food Support}

Most participants expressed a positive attitude toward the assistance they received, in terms of both their own feelings and the way they were treated by the volunteers, and they were grateful for the help.

Menachem: You can say it's a positive experience because I know it helps me and I accept that. I feel okay about it, I feel good.

Dorit: I feel very good. I regard it as a source of strength, support. Someone has your back, to raise you up, a security blanket. Like a child who needs an encouraging word or something and when he gets it he gets the power to do things. A sort of confidence in yourself that you can better yourself.

However, although the participants felt they were treated warmly and respectfully by the volunteers in meal centers and food banks, they did not sense the same attitude from other people.

Sarah: I don't feel bad because everyone here has a hard life. But I think there's a different attitude in the rest of society.

Moshe: I get along well with people...but not always. There are also people who look at me as if I'm a bad person.

David sensed an even more negative attitude toward him:

People don't want to be friends with us, as if we're lepers.

A number of participants related to the issue of shame and the fact that society pities recipients of food support. The difficulty of dealing with this problem is reflected in the remarks of Shoshana, who actually distanced herself from the situation by referring to herself in the third person, saying:

It's not easy. It's embarrassing. They're looked at like people to be pitied...often looked down on. But anyone can find himself in this situation. People aren't to blame for having gotten to this state.

In contrast, Dinah claimed:

I feel fine. I'm not ashamed. I'm not stealing anything...Me, I don't eat anything. I'm concerned for the children...that they eat, that they have food. If they don't, I feel the pressure about where I'm going to get it from.

An important aspect of the issue of shame is discretion, a subject several participants raised. As Shlomit explained: 
Before the holidays when I went places...I had to wait in line for hours...It was embarrassing. Today they bring the food to me. It's very respectful now...It's discrete and considerate, and it's a big help.

Nevertheless, some interviewees stated that they still feel ashamed, but they recognize that they have no choice. In Tamar's words:

It's not pleasant. People look at you. But what can I do? I have to eat.

\section{Theme 4: Effect of Assistance on Food Security}

Most participants were pleased with the improvement in their situation as a result of the assistance they received. They were happy that they could rely on their nutritional needs being met, and that they were able to take care of other necessities now that they did not have to worry about food. As Dorit described it:

First of all, it helps very very much. The financial situation is obvious... When they help with vegetables or fruit or clothes or shoes, I repay my debts.

Ronit stressed the emotional aspect.

On the emotional level, I know I can count on having food. There won't be a situation when I don't have food. That's a very good feeling.

On the other hand, several interviewees referred to what they were still lacking.

Tamar: I don't get a lot. My sister and I buy most things. We help each other out.

Those taking advantage of meal centers noted the positive effect of having a reliable source of food. As Sarah stated:

I know I'll have a regular meal every day. I'm not worried...It helps to know I won't go hungry today because of places like that.

On the negative side, however, the meal centers do not satisfy all the recipients' food requirements. In the words of Moshe:

I can count on it. I know there's always food here and I don't have go looking. But they only serve lunch so sometimes I'm hungry at night and I buy something to eat.

\section{Theme 5: Responsibility for Food Security}

In the opinion of most participants, it is the responsibility of the state to ensure that people have enough money for food and other basic necessities. They note that today that role is being performed by NGOs, and are highly critical of the government's handling of the problem. Shlomit's remarks reflect the general consensus.

The government doesn't help at all. They raise prices... They could do a lot more to help, but they don't think about the people who need it ... the people who are hard up...They give you so much red tape and talking and forms. It's a big headache and a minimum of aid. They send you some place far away and that doesn't make it easier. That's not what it means to help. They have to think about how to help people in the best way possible. The volunteer organization ...never asked us to fill out forms...At the moment, the organizations are responsible for it and they're doing it well. 
Interviewees also raised other problems, including not being able to access the assistance they are entitled to, and the fact that state welfare benefits are insufficient. In addition, they referred to the responsibility of the individual. Dinah, for example, noted the need to work alongside government obligations.

The welfare system has to look out for people in need. They should make sure that people have a job. You can't be dependent on them all the time. That goes for a lot people, not just me.

\section{DISCUSSION}

This study presents the voices of people receiving assistance to promote their food security. In order to prevent undesirable circumstances, such as long-term dependency on external sources for nutritional needs and diminished personal responsibility, Israel adopted a strategy implemented in many Western countries. It provides welfare benefits rather than actual services, along with food support programs designed to improve the food security of the older adults and children. The National Food Security Law passed in 2011 aimed to promote food security for all residents of Israel.

Most of the interviewees in this study noted their belief that the state should be more concerned for food security and take responsibility for it. They viewed food security as a right they were entitled to as recipients of welfare benefits. However, they stressed that the benefits they received were too low to enable them to fulfill their basic needs. As a result, they turned for assistance to volunteer organizations.

Their need for food support stemmed primarily from economic hardship, that is, low income whether from work or from welfare benefits. On the whole, the request for assistance came after they had exploited all other options, including turning to family and friends for help and exhausting their savings. Parents were motivated to ask for aid mainly by their desire to protect their children and ensure that their nutritional needs were met. This is consistent with the findings of previous studies showing that parents suffering economic hardship are concerned that they will not be able to provide food for their children (Bove \& Olson, 2006; De Marco \& Thorburn, 2009; Nord et al., 2009). Indeed, our interviews indicate that the children in the family are shielded more from food insecurity than the adults.

Also in line with earlier studies (Booth et al., 2018a; Booth et al., 2018b; Middleton et al., 2018) the interviewees in our study reported that the food they received was not always appropriate, and consequently they did not eat some of the items they were given. Alongside their gratitude for the assistance and their appreciation of the way they were treated by the volunteers, they were critical of the type and quantity of the food in terms of its suitability for the family's needs. They also noted their preference for payment cards that allow them autonomy and enable them to purchase their food in a socially acceptable manner.

In regard to the emotional response to receiving assistance, most participants expressed positive feelings. On the whole, they do not feel ashamed and appreciate the support and the attitude of the people in the organizations. These feelings are linked to discretion in the manner in which the aid is provided, and to the sense that they are treated with respect and consideration. The positive attitude toward charity for the poor and hungry may derive from Jewish sources and the fundamental commandment, "When you reap the harvest of your land you shall not reap all the way to the edges of your field, or gather the gleanings of thy harvest. You shall not pick your vineyard bare, or gather the fallen fruit of your vineyard; you shall leave them for the poor and stranger" (Lev. 19:9-10). Nevertheless, some participants spoke of a sense of shame, embarrassment, and discomfort. The harsh comment of one participant, "There are people look at me as if I'm a bad person," may be allied with society's stereotype of the poor as "others," that is, people who have failed in life and are to blame for their impoverishment. Indeed, a previous study conducted in Israel (Cohen et al., 2017) found that as a result of the stigma associated with meal centers, those who ate there were no longer regarded as "regular" people, but as "others." Similarly, in studies in the US (Middleton et al., 2018; Parks et al., 2019), recipients of assistance reported a negative experience accompanied by feelings of shame, humiliation, stigma, and judgmental attitudes toward them. 
Another issue examined here is whether the assistance provided is, in fact, effective. Most of the participants expressed satisfaction with the improvement in their food security, and noted that the food support they received enabled them to use their money to meet other needs. They repeatedly stated that they felt they had a safety net in regard to food. However, several reported that they were still lacking in this respect, indicating that the assistance provided by NGOs does not entirely extricate them from food insecurity. Similarly, a study conducted in Canada (Holmes et al., 2019) found that food bank use does not ameliorate severe household food insecurity. Nonetheless, the fact that they are not alone and have somewhere to turn in times of need affords them a certain sense of security. This is in line with previous studies (Middleton et al., 2018; Parks et al., 2019) showing that while food banks do not constitute the ultimate solution to the problem of food insecurity, they improve the individual's situation, reduce economic pressure, and enable money to be used for other necessities.

\section{Limitations and Recommendations for Future Studies}

The current study opens a window on the world of the recipients of food support by presenting their own perspective. However, as this is a qualitative study, the sample is small and does not pretend to represent the entire population of those receiving such assistance. A quantitative study might be able to provide a fuller picture. In addition, all the participants were Jewish Israelis. Future studies might expand the examination to other ethnic groups in Israel.

\section{Conclusions and Practical Recommendations}

The findings indicate the importance of considering the opinions of those in need when making policy decisions regarding food security. This approach can help in determining the most effective means of ameliorating their situation in providing the basic, vital and healthy human need for food security. In view of the economic reality today, and particularly the COVID-19 pandemic that has left many people jobless and in need of help to meet their basic food requirements, there appears to be a continued demand for nongovernment organizations to provide the necessary assistance. For instance, a recent study (Fitzpatrick et al., 2020) shows the importance of redesigning food systems for socially vulnerable, fearful, persons in poorer health, and those with higher levels of depressive and anxiety symptoms who have higher food insecurity odds. In addition, O'Hara \& Toussaint (2021) emphasizes community-centered strategies that help break down existing socio-political barriers in a time of crisis, and help shift the discourse of food to a broader goal of community empowerment.

General conclusions from the findings of our study are that efforts should be made to suit the items provided to the specific families, and to offer help in a manner that enables the recipients to maintain their dignity. Furthermore, the possibility of expanding the use of payment cards should be considered, along with increased training in money management.

Our practical recommendations stemming from the study, and according to the situation created by the pandemic (COVID-19) are: (a) to increase the government's direct financial support to the needy families, (b) to allow organizations that provide food assistance to use existing resources such as transporting food to family homes, (c) to strengthen the activities of local councils through social workers to find all the people and families in need of food aid, and provide the required assistance.

\section{REFERENCES}

Bickel, G., Nord, M., Price, C., Hamilton, W.L., \& Cook, J.T. (2000). Guide to household food security, revised 2000. U.S. Department of agriculture, food and nutrition service. Retrieved from https://fns-prod.azureedge.net/sites/default/files/FSGuide.pdf

Booth, S., Begley, A., Mackintosh, B., Kerr, D.A., Jancey, J., Caraher, M., . . Pollard, C.M. (2018a). Gratitude, resignation and the desire for dignity: lived experience of food charity recipients and their recommendations for improvement, Perth, Western Australia. Public Health Nutrition, 21(15), 2831-2841. doi:10.1017/S1368980018001428

Journal of Applied Business and Economics Vol. 23(4) 2021221 
Booth, S., Pollard, C., Coveney, J., \& Goodwin-Smith, I. (2018b). 'Sustainable' rather than 'Subsistence'. Food assistance solutions to food insecurity: South Australian recipients' perspectives on traditional and social enterprise models. International Journal of Environmental Research and Public Health, 15(10), 1-18. doi: 10.3390/ijerph15102086

Boyact-Gündüz, C.P., Ibrahim, S.A., Wei, O.C., \& Galanakis, C.M. (2021). Transformation of the Food Sector: Security and Resilience during the COVID-19 Pandemic. Foods, 10(3), 497. MDPI AG. http://dx.doi.org/10.3390/foods 10030497

Cohen, Y., Krumer-Nevo, M., \& Avieli, N. (2017). Bread of shame: Mechanisms of othering in soup kitchens. Social Problems, 64(3), 398-413. Doi: 0.1093/socpro/spx011

Coleman-Jensen, A., Rabbitt, M.P., Gregory, C.A., \& Singh, A. (2019). Household Food Security in the United States in 2018. A report summary from the Economic Research United States Department of Agriculture. Retrieved from https://www.ers.usda.gov/webdocs/publications/94849/err270_summary.pdf?v=963.1

Davis, O., \& Geiger, B.B (2017). Did food insecurity rise across Europe after the 2008 crisis? An analysis across welfare regimes. Social Policy and Society, 16(3), 343-360. Doi: $10.1017 / \mathrm{S} 1474746416000166$

De Marco, M., Thorburn, S., \& Kue, J. (2009). "In a Country as Affluent as America, People Should be Eating": Experiences With and Perceptions of Food Insecurity Among Rural and Urban Oregonians. Qualitative Health Research, 19(7), 1010-1024. https://doi.org/10.1177/1049732309338868

Endeweld, M., Goldsmith, R., \& Endevelt, R. (2018). The demographic and morbidity characteristics of a population receiving food support in Israel. Israel Journal of Health Policy Research, 7(1), 1-12. DOI 10.1186/s13584-018-0238-8

Endeweld, M., Heler, O., Barkali, N., \& Gottlieb, D. (2018). Food Security Survey 2016. National Insurance Institute. Retrieved from https://www.btl.gov.il/Publications/research/Pages/mechkar_127.aspx

Farhat, D., Kunkel, D.R., \& Quesenberry, J. (2019). Peaked Interest: Public Interest in Hunger and the Economic Cycle. Journal of Applied Business \& Economics, 21(7), 25-38. Retrieved from proquest.com/docview/2336296347?pq-origsite $=$ gscholar\&fromopenview $=$ true

Fiitzpatrick, K.M., Harris, C., Drawve, G., \& Willis, D.E. (2021). Assessing Food Insecurity among US Adults during the COVID-19 Pandemic. Journal of Hunger \& Environmental Nutrition, 16(1), 118. DOI: $10.1080 / 19320248.2020 .1830221$

Holmes, E., Fowokan, A., Seto D., Lear, S.A. \& Black, J.L. (2019). Examining food insecurity among food bank members in Greater Vancouver. Journal of Hunger \& Environmental Nutrition, 14(12), 141-154. https://doi.org/10.1080/19320248.2018.1465001

Kansiime, M.K., Tambo, J.A., Mugambi, I., Bundi, M., Kara, A., \& Owuor, C. (2021). COVID-19 implications on household income and food security in Kenya and Uganda: Findings from a rapid assessment. World Development, 137. https://doi.org/10.1016/j.worlddev.2020.105199

Kent, K., Murray, S., Penrose, B., Auckland, S., Visentin, D., Godrich, S., \& Lester, E. (2020). Prevalence and Socio-Demographic Predictors of Food Insecurity in Australia during the COVID-19 Pandemic. Nutrients, 12(9), 2682. doi: 10.3390/nu12092682. PMID: 32887422; PMCID: PMC7551067

Leisinger, K.M., Schmitt, K., \& Pandya-Lorch, R. (2002). Six billion and counting: population and food security in the $21^{\text {st }}$ century. Washington, D.C.: International food policy research institute.

Retrieved from http://www.ifpri.org/publication/six-billion-and- counting

Loopstra, R., Reeves, A., \& Stuckler, D. (2015). Rising food insecurity in Europe. The Lancet, 385(9982). DOI:10.1016/S0140-6736(15)60983-7

Loopstra, R., Reeves, A., Mckee, M., \& Stuckler, D. (2016). Food insecurity and social protection in Europe: Quasi-natural experiment of Europe's great recessions 2004-2012. Preventive Medicine, $89,44-50$. 
Middleton, G., Mehta, K., McNaughton, D., \& Booth, S. (2018). The experiences and perception of food banks amongst users in high-income countries: An international scoping review. Appetite, 120(1), 698-708. https://doi.org/10.1016/j.appet.2017.10.029

Mousa, T.Y., \& Freeland-Graves, J.H. (2019). Food security of food recipients of a food pantry and soup kitchen. Public Health Nutrition, 22(8), 1451-1460. https://doi.org/10.1017/S1368980018003658

Nord, M., Andrews, M., \& Carlson, S. (2009). Household food security in the United States, 2008. Economic research report (ERR-83). United States department of agriculture. Retrieved from http://www.ers/usda.gov/Data

O'Hara, S., \& Toussaint, E.C. (2021). Food access in crisis: Food security and COVID-19, Food access in crisis: Food security and COVID-19. Ecological Economics, 180. https://doi.org/10.1016/j.ecolecon.2020.106859

Owen, D., \& Baumberg, B.B. (2017). Did Food Insecurity rise across Europe after the 2008 Crisis? An analysis across welfare regimes. Social Policy and Society, 16(3), 343-360. https://doi.org/10.1017/S1474746416000166

Owens, M.R., Brito-Silva, F., Kirkland, T., Moore, C.E., Davis, K.E., Patterson, M.A., . . Tucker, W.J. (2020). Prevalence and Social Determinants of Food Insecurity among College Students during the COVID-19 Pandemic. Nutrients, 12(9), 2515. https://doi.org/10.3390/nu12092515

Parks, C., Calloway, E., Chiappone, A., Fricke, H., Stern, K., \& Yaroch, A.L. (2019). Perceptions of SNAP Policies among food pantry clients in the Midwest: A comparison between SNAP and non-SNAP participants. Journal of Hunger \& Environmental Nutrition, 14(1-2), 82-97. Doi: $0.1080 / 19320248.2018 .1549519$

Patrice, R.Z., Somlanare, R.K., \& Idrissa, M.O. (2020). Could Covid-19 Worsen Food Insecurity in Burkina Faso? The European Journal of Development Research, 32(5), 1379-1401. DOI: 10.1057/s41287-020-00324-6

Pettoello-Mantovani, M., Ehrich, J., Sacco, M., Ferrara, P., Ida Giardino, I., \& Pop, T.L. (2018). Food insecurity and children's rights to adequate nutrition in Europe. The Journal of Pediatrics, 198(0022-3476), 329-330. https://doi.org/10.1016/j.jpeds.2018.04.042

Piaskoski, A., Reilly, K., \& Gilliland, J.A. (2020). A conceptual model of rural household food insecurity. Family and Community Health, 43(4), 296-312. doi: 10.1097/FCH.0000000000000273

Pruitt, S.L, Leonard, T., Xuan, L., Amory, R., Higashi, R.T., Nguyen, O.K., \& Swales, S. (2016). Peer Reviewed: Who is food insecure? Implications for targeted recruitment and outreach, national health and nutrition examination survey, 2005-2010. Preventing Chronic Disease, pp. 13-15. doi: $10.5888 /$ pcd13.160103

Reeves, A., Loopstra, R., \& Stuckler, D. (2017). The growing disconnect between food prices and wages in Europe: cross-national analysis of food deprivation and welfare regimes in twenty-one EU countries, 2004-2012. Public Health Nutrition, 20(8), 1414-1422. DOI:10.1017/S1368980017000167

Smith, J.A., \& Osborn, M. (2003). Interpretative phenomenological analysis. In J.A. Smith (Ed.), Qualitative psychology: A practical guide to research methods (pp. 51-81). SAGE.

Smith, J.A., Flowers, P., \& Larkin, M. (2009). Interpretative phenomenological analysis: Theory, method and research. SAGE. 